\title{
EL NACIONALISMO MUSICAL EN EL ECUADOR. ENFOQUE EN EL COMPOSITOR ECUATORIANO GERARDO GUEVARA
}

THE MUSICAL NACIONALISM IN ECUADOR. APPROACH IN ECUADORIAN COMPOSER GERARDO GUEVARA

\section{CLAUDIO VITERI VILLAMAR}

Universidad Católica de Santiago de Guayaquil, Ecuador. viteriba@cu.ucsg.edu.ec

RESUMEN

El presente artículo relaciona dos conceptos importantes: nacionalismo y música. El nacionalismo surgió en países que estaban colonizados o gobernados por un país extranjero y deseaban la autonomía o independencia. Por su parte, el concepto de música es entendido como el arte de interrelacionar los sonidos a través del ritmo, la melodía y la armonía. La música es un medio a través del cual es posible expresar el nacionalismo de un país. Diferentes recursos pueden ser la pintura, la escultura, la literatura, entre otros. El concepto de nacionalismo no es nuevo, nace en Europa a partir del siglo XIX y más específicamente a partir de 1830 en que las artes fueron los principales medios para manifestar la identidad nacional. Coincidiendo este año además, con la independencia de la República del Ecuador, y su establecimiento como país libre e independiente. Así como el nacionalismo tiene sus defensores, también tiene sus opositores, quienes manifiestan que dicho concepto impone criterios rígidos y no admite posturas intermedias. En este trabajo, se describe al Ecuador en dos momentos históricos: antes y después del descubrimiento de América por parte de los españoles. De igual forma, se describe y explica el concepto de nacionalismo musical en el Ecuador, con enfoque en el compositor ecuatoriano Gerardo Guevara y los géneros musicales por él utilizados en la mayoría de sus obras.

PALABRAS CLAVE: nacionalismo musical, identidad nacional, música andina, colonización, mestizaje.
ABSTRACT
The present research connects two important concepts: nationalism and music. The nationalism emerges in countries that wished their autonomy and were governed by other foreing country, on the other side, the concept of music, which is the art of mix the sounds through the rhythm, the melody and the harmony. The music is a way through which is possible to show the nationalism of a country, other ways are the painting, the sculpture, the literature, among other. The concept of nationalism is not new, it started in Europe from XIX century and more specifically since 1830 , when the arts were the main ways to show the national identity. This same year of 1830 also coincides with the independence of the Republic of Ecuador, as free and independent country.As the nationalism has its defenders, also have its opponents, who think that this concept establish rigids points of view and not admit intermediate options. Through the development of the present research, the Ecuador is described in two historic moments: before and after of the America's discovery from Spanish conquerors, describes and explains the musical nationalism concept in Ecuador with approach on Gerardo Guevara composer and the musical genders used by him, in the most of his musical compositions.

KEYWORDS: MUSICAL nationalism, national identity, andean music, colonization, mestization 
INTRODUCCIÓN

El concepto de nacionalismo es un tema fascinante y muy amplio, detrás del cual existen muchas historias. No obstante, falta mucho por investigar y aprender todavía, ya que a pesar de ser un tema muy conocido y abordado, tiene una aplicación particular e individual en función del país en donde se lo aborde y estudie.

Como la palabra lo indica, nacionalismo proviene de nación, por lo que podría decirse que es el sentimiento de pertenencia a la nación de cada persona. Algo similar al patriotismo, pero más amplio, pues va más allá del sentimiento e incluye contenido doctrinal o acción política en un sentido concreto. Un ejemplo de ello, lo representa el compositor húngaro Béla Bártok, nacido en 1881 y fallecido en 1945, quien vitalizó su música con los temas, modos y patrones rítmicos de la música folclórica húngara tradicional.

Algunos países relacionados con el nacionalismo son: Polonia, Rusia, Rumanía, Hungría, Noruega, Finlandia, Suecia, Ucrania, España, Reino Unido, Estados Unidos, México, Brasil, Argentina, Chile, Cuba, Venezuela y Ecuador, entre otros.

Es importante anotar que, así como el nacionalismo tiene sus defensores, también tiene sus opositores. Estos últimos, consideran que el nacionalismo divide a las personas y destruye el lado bueno de la naturaleza humana. El problema del pensamiento nacionalista se da en que impone su criterio, es rígido y no admite posturas intermedias.

METODOLOGÍA

El artículo combina la investigación histórica, documental, descriptiva y explicativa, derivado de una investigación básicamente cualitativa, donde fueron utilizados los métodos deductivo e inductivo, así como fuentes de investigación primarias y secundarias (Bernal, 2010, p. 191). Entre las fuentes primarias, se contactó al propio compositor a quien le fue realizada una entrevista. Se revisaron además, libros y partituras del compositor Guevara. Entre las fuentes secundarias fueron consultados libros y revistas que contienen opiniones de compositores y críticos musicales entendidos en la materia.

DESARROLLO

EL ECUADOR ANTES DEL DESCUBRIMIENTO DE AMÉRICA

Antes de la llegada de los españoles, el hoy denominado Ecuador, estaba habitado y manejado por los Incas. Huayna-Capac, hijo de Tupac
Yupanqui ${ }^{1}$, lideraba el Tahuantinsuyo. El Inca Huayna-Capac había escuchado sobre la llegada de unos desconocidos, los españoles, noticia que lo habría llenado de profunda tristeza, pues sobre el imperio pesaba la profecía de Viracocha de que "el día que hombres blancos y barbados llegaran hasta las costas de su imperio, ese día empezaría el fin del Tahuantinsuyo" (Lalama, 2011, p. 211).

Antes de morir, Huayna-Capac habría dado a conocer su última voluntad, la división del imperio entre sus hijos Huáscar, a quien le deja el sur del Tahuantinsuyo (actualmente Perú), mientras que Atahuallpa heredaría el norte del imperio (actualmente Ecuador). La decisión de Huayna-Capac no fue aceptada por Huáscar, enfrentándose los hermanos en cruentas guerras hasta que, finalmente, venció Atahuallpa. Lamentablemente, Atahuallpa y Huáscar no se llevaban bien y estaban divididos, lo cual representó una ventaja para los españoles en sus objetivos de conquistar América.

\section{COLONIZACIÓN E IDENTIDAD NACIONAL EN EL ECUADOR}

El 12 de octubre de 1492 los españoles invadieron América. A partir de ese momento, los incas fueron obligados a ingresar al mundo occidental. La astucia del europeo, la pólvora y el caballo fueron las armas del conquistador. "Los españoles vinieron con un triple objetivo: ganar tierras para el imperio, oro para el monarca y almas para el cielo cristiano" (Samaniego, 2008, p.40).

Se produjo lo que para los agredidos se denomina, imposición cultural, genocidio cultural, transculturación, deculturación progresiva, aculturación y para los agresores adaptación, pacificación y conciliación. Francisco Morales Padrón (1962), catedrático de la Universidad de Sevilla en su obra "Manual de Historia Universal”, tomo VI escribió:

El encuentro entre las dos razas se tradujo, con todas sus consecuencias, en un titánico esfuerzo por parte del pigmento europeo tendente a elevar a su nivel cultural al pigmento americano, hundido en tres mil años de atraso". Más adelante agrega: "Para el indio, el español fue un intruso o un dios. Alguien que venía a aposentarse en su horizonte geográfico, a derribar sus dioses y a tomar las mujeres de su tribu. Se defiende de él, lo rechaza o acaba replegándose mientras sus

Inca, hijo de Pachacutec y nieto de Huiracocha. 
mujeres se entregan al blanco para originar lo mestizo. Es a través de la india que le llega al mestizo el pigmento amarillo, para el vejamen del indio que no tiene acceso a la mujer blanca (Morales, 1962, p. 332).

A continuación se cita el poema ¿Encuentro?, escrito por la doctora Katia Murrieta², quien describe en forma precisa la situación anteriormente tratada:

¿Habremos cambiado el descubrimiento? Ahora se dice fue sólo un encuentro, Que no hubo yugo, que no fue un duelo, Que de las dos razas surgió algo nuevo. Sin embargo hay algo que olvidar no puedo: Las indias violadas, el fado desecho, Los indios esclavos y sus hijos muertos, El trabajo en minas, el pago de diezmos. Si acepto el encuentro, ¿qué dices Bolívar? ¿Acaso sufriste por una quimera? Tú moriste solo, en un catre ajeno, Lejos de Angostura, sólo con un sueño. ¿Tú crees que no hubo masacre en el pueblo? ¿Piensas que luchaste sin tener que hacerlo, Que cinco naciones no fueron tu éxito? No, Bolívar, no, nada de esto es cierto. La sangre mestiza se metió en el cuerpo Y negros y blancos mezclaron su ancestro. Para todos hubo un gran vientre abierto, Cambiaron los genes, torcieron las huellas. Nacía una raza, de otra vencida, Y el indio yació tumbado en la yerba. El sol de las doce quemó su garganta Y un verbo lejano mató su palabra. Abajo los dioses, abajo las lanzas, Dios es sólo uno, de cara muy pálida, No esperes del sol, la luna o el agua, "ruega por nosotros" en vez de la danza. América, España, en países hermanos, Luchemos unidos por una esperanza, Levantemos al indio, que es también humano,

Pero no digamos que no fue un esclavo $\left(\mathrm{Mu}^{-}\right.$ rrieta, 1992, p. 36).

Es decir el encuentro entre los españoles y los indígenas no fue un encuentro amistoso, fue de dominación del blanco al indio, el cual aparentemente aceptó esta situación en un primer momento, y más tarde se revelaría. En lo musical se produjo un interaprendizaje. Los

2 Abogada, escritora, poeta y destacada artista guayaquileña. frailes franciscanos, los agustinos, los jesuitas y las monjas enseñaron música europea a los indígenas.

La música, la enseñanza musical, la composición y la difusión, durante la época colonial estaban al servicio y bajo el control de la religión católica. Los frailes y monjas impusieron en $\mathrm{La}^{-}$ tinoamérica los patrones estéticos vigentes en Europa. Los templos, monasterios y conventos fueron los principales centros donde se desarrolló la actividad musical.

Múltiple también, fue el aporte de África a la música ecuatoriana. Desde el siglo XVI al siglo XIX, nueve millones de africanos fueron traídos a América.

En octubre de 1553, un navío sevillano que viajaba desde Panamá al Perú, naufragó al sur de la actual ciudad de Esmeraldas, por lo que 23 negros esclavos (17 hombres y 6 mujeres) que iban a ser vendidos en Lima, obtuvieron su libertad, escondiéndose en la selva, mientras sus dueños morían de hambre y fatiga (Godoy, 2007, p. 61).

Algunos de los instrumentos de la música esmeraldeña que se desarrollaron fueron: la marimba, el bombo esmeraldeño, el bombo de agua, el cununo, la guasá, las maracas y la charrasca.

La mezcla de los españoles con los indios y negros dio como resultado a los criollos y los mestizos, quienes al avergonzarse de su nueva raza, no la reconocen ni aceptan. Esto ocasiona que exista una pobre identidad nacional en el Ecuador.

La conquista de América por parte de los españoles trajo consecuencias negativas y positivas. Entre las negativas se puede citar el uso de la fuerza para imponer una nueva cultura. Siendo destacadas como positivas, la enseñanza del arte de la música y la pintura a los indígenas, así como la religión católica.

En 1822 el Ecuador logró independizarse de España y formó parte de la Gran Colombia con Venezuela y Colombia. Una vez disuelta la Gran Colombia en 1830, el Ecuador se constituyó en una República Independiente, luego de largas guerras independentistas.

\section{NACIONALISMO MUSICAL EN EL ECUADOR}

Desde el punto de vista cultural, para que exista nacionalismo debe existir una cultura que se opone a la otra. En el Ecuador, el nacimiento del nacionalismo se produce por la oposición 
de dos culturas musicales distintas: la europea versus la local o tradicional. El desarrollo del nacionalismo musical depende de cómo se desenvuelve este conflicto en la obra de los compositores ecuatorianos, quienes fusionaron las dos culturas y las transformaron en obras que fueron finalmente, resultados musicales técnicamente sofisticados.

El nacionalismo cultural define la nación en términos de etnicidad, lo cual siempre incluye algunos elementos descendientes de las generaciones pasadas. También contiene ideas de una conexión cultural entre los miembros de la nación y sus antepasados.

El nacionalismo en música, se refiere al uso de materiales que son reconocibles como nacionales o regionales. Por ejemplo, el uso de la música folclórica y el uso de melodías, ritmos y armonías inspirados por la misma. El nacionalismo también incluye el uso del folclor ${ }^{3}$ como base conceptual, estética e ideológica de obras programáticas y óperas.

El nacionalismo también ha sido relacionado con el romanticismo musical de mediados del siglo XIX hasta mediados del siglo XX. Algunos ejemplos de compositores nacionalistas en otros países fueron Frederick Chopin, en Polonia; Isaac Albéniz, Enrique Granados, Joaquín Turina y Manuel de Falla, en España; y Béla Bartók, en Hungría. Este último, arranca del nacionalismo para llegar en sus últimas composiciones a la abstracción musical. Recogió en sus obras, ritmos exóticos y desconocidos, así como escalas primitivas como la pentafónica (de cinco tonos). Todo ello unido a la excelente formación técnica, le hizo componer con un lenguaje audaz que constituye una de las grandes revoluciones de la música en el siglo XX.

Entre los primeros compositores nacionalistas ecuatorianos estuvieron Francisco Salgado ${ }^{4}$, Sixto María Durán ${ }^{5}$, Segundo Luis Moreno ${ }^{6}$, quienes se formaron en el Conservatorio Nacional de Música con maestros italianos. En una segunda generación de compositores nacionalistas ecuatorianos figuran Luis Humberto Sal-

3 Conjunto de tradiciones, leyendas, creencias, costumbres y proverbios populares.

4 (1880-1970) Compositor, crítico musical, pianista y director de banda cayambeño.

5 (1875-1947) Compositor y pianista quiteño.

6 (1882-1972) Musicólogo, compositor y director de banda nacido en Cotacachi (Imbabura). gado7, Carlos Bonilla Chávez ${ }^{8}$, Claudio Aizaga ${ }^{9}$, Gerardo Guevara, entre otros. Entre las obras musicales nacionalistas del compositor Luis Humberto Salgado, quien fue maestro de Gerardo Guevara, destacan la Sinfonía Andina ${ }^{10}$ y la Suite Atahuallpa ${ }^{11}$.

\section{EL ESPÍRITU NACIONALISTA DEL COMPOSITOR ECUATORIANO GERARDO GUEVARA}

Cien años más tarde de que el Ecuador se constituyera como República independiente en 1930, el 23 de septiembre nace en Quito el compositor Luis Gerardo Guevara Viteri. Nacimiento que tiene lugar en el antiguo Conservatorio Nacional de Música, rodeado de un ambiente musical, pues su padre laboró allí por muchos años.

Gracias a una beca que le otorgó el entonces director del conservatorio, Dr. Sixto María Durán, Gerardo Guevara estudió allí inicialmente oboe, lo que le permitió integrar la orquesta sinfónica del conservatorio donde estudiaba. Posteriormente, estudiaría violín, piano, saxofón, así como las materias complementarias (teoría de la música, solfeo, dictado, historia de la música, armonía, composición y fuga, entre otras).

En 1959llega a París, becado por la UNESCO ${ }^{12}$. Allí estudió con la prestigiosa maestra Nadia Boulanger ${ }^{13}$, quien había sido profesora de importantes compositores tales como Astor Piazzola, Philip Glass, Aaron Copland, entre otros.

En 1972 el compositor Guevara regresa a su ciudad natal y en marzo del mismo año es nombrado director del coro de la Universidad Central del Ecuador. A mediados de este mismo año, recibe también el nombramiento de director de la Orquesta Sinfónica Nacional. Entre 1980 y 1988 estuvo al frente de la Dirección del Conservato-

(1903-1977) Compositor, pianista y crítico musical cayambeño.

8 (1923-2010) Guitarrista, compositor y contrabajista quiteño.

9 (1926-2008) Pianista y compositor quiteño.

10 Composición orquestal. Consta de cuatro movimientos: Sanjuanito, Yaraví, Danzante y Albazo.

11 Composición para banda sinfónica, de tres partes: Preludio, La fiesta del Sol y la Tragedia de Cajamarca.

12 Sigla de United Nations Educational Scientific and Cultural Organization, institución dependiente de las Naciones Unidas, fundada en 1946, con el fin de contribuir a la paz mediante el desarrollo de la cultura y la ciencia.

13 (1887-1979) Compositora, directora de orquesta y profesora francesa. 
rio Nacional de Música de Quito, realizando algunas composiciones con fines didácticos.

Dos grandes maestros de Gerardo Guevara influyeron en su carácter nacionalista: el compositor ecuatoriano Luis Humberto Salgado y el maestro Jorge Rayki ${ }^{14}$. Con éste último, Guevara estudió la obra de Béla Bartók ${ }^{15}$.

El compositor Guevara, a través de su música representa o es, la voz del pueblo indígena de la sierra ecuatoriana. Utiliza tonalidades menores así como la pentafonía ${ }^{16}$ andina en la mayoría de sus composiciones. Utiliza géneros musicales andinos tales como el Yaraví, el Danzante, el Yumbo, el Sanjuanito y el Pasillo para reflejar su carácter nacionalista. En las letras de la mayoría de sus canciones andinas utiliza el quichua ${ }^{17}$ como idioma nacional.

Como ejemplo de lo mencionado anteriormente, se ilustra a continuación un fragmento de la letra del Yumbo, Apamuy Shungo (compuesto en 1957), que aparece en Lovato (2013), y que significa entregando el corazón.

Jatun rupay can apamuy cansay cunuy Jatun rupay cuyaranchi, tucuy shungo. Tarpuranchi allpa, ricu ranchi churi

Tayta yucapaag, tayta tucuy pag

Jatun Rupay. (p. 25).

Que en español significa:

Gran Sol, tú eres vida y calor

Gran Sol, te adoramos con todo corazón

Sembraremos la tierra

Cuidaremos tus hijos

Padre mío, padre de todos.

Con Gerardo Guevara, el nacionalismo se vuelve radical, extremo, no admite posturas intermedias. Lo indígena es el lenguaje puro y lo puro es, por lo tanto, lo más importante en un discurso cargado de emotividad sincera, que rompe con la tradición europea y dibuja un horizonte personal único y pragmático (Lovato, 2013, p. 69).

A pesar del evento colonizador y de haber tenido influencia europea, el compositor Gerardo Guevara mantuvo su estilo nacionalista. En la realización de su obra musical coincide con

14 (1921 - ) Compositor y director húngaro.

15 (1881-1945) Compositor y pianista húngaro.

16 Escala indígena de la sierra ecuatoriana compuesta por cinco sonidos como referencia.

17 Idioma de los incas. los artistas plásticos Oswaldo Guayasamín ${ }^{18}$ y Eduardo Kingman ${ }^{19}$ los cuales rescatan y dan énfasis a la población indígena ecuatoriana, en su realidad de marginación y sufrimiento. En la literatura coincide también con escritores tales como Jorge Icaza ${ }^{20}$ y Benjamín Carrión ${ }^{21}$ con sus obras Huasipungo y Atahuallpa, respectivamente.

PRINCIPALES GÉNEROS MUSICALES UTILIZADOS POR EL COMPOSITOR GERARDO GUEVARA

A finales del siglo XIX e inicios del siglo XX, se consolidaron algunos de los géneros $\mathrm{mu}^{-}$ sicales existentes, e innovaciones musicales regionales. En la mayoría de ellos se evidencia el sentimiento nacionalista de la época. En esa etapa histórica, aparecieron las primeras composiciones de los músicos que estudiaron en el Conservatorio Nacional de Música de Quito, fundado por el presidente Gabriel García Moreno (1870-1877).

Los géneros musicales andinos utilizados por el compositor Gerardo Guevara no constituyen un fin en sí mismo, son medios a través de los cuales, el compositor refleja su espíritu o carácter nacionalista en este caso. Cabe indicar que,

Lo andino es un vocablo que no alude exclusivamente a la zona geográfica atravesada por la cordillera de los Andes ${ }^{22}$, es un proyecto de identidad e integración y un proceso cultural dinámico. La música andina es la música de estos pueblos, de estas culturas, como resultado de la evolución del tiempo, por indios, criollos, mestizos, entre otros, por una sociedad injustamente jerarquizada, es una música actual y en constante renovación (Godoy, 2007, p. 39).

Entre los principales géneros musicales utilizados por el maestro Guevara están:

- El Yaraví: canto sentimental de carácter musical andino. Se escribe en compás de $6 / 8$, triste, tempo andante. Tonalidad menor.

8 (1919-1999) Pintor quiteño.

19 (1913-1998) Pintor lojano.

20 (1906-1978) Escritor y director teatral quiteño.

21 (1897-1979) Escritor, poeta y abogado lojano.

22 Cadena de montañas que ocupa la zona occidental de América del Sur. Atraviesa los territorios de Argentina, Chile, Bolivia, Perú, Ecuador, Colombia y Venezuela. 
- El danzante: danza andina, producto de la innovación de antiguas danzas indígenas, vigente básicamente en la región andina. Se escribe en compás de 6/8, carácter religioso, tempo allegreto.

- El Yumbo: canción y baile mestizo. Se escribe en compás de $6 / 8$, carácter guerrero, tempo allegro molto. Ejemplo: Apamuy Shungu (Dame el corazón) del compositor Gerardo Guevara.

- La tonada: danza con texto de carácter popular. Se escribe en compás binario de $6 / 8$ en tonalidad menor. Ejemplo: Tonada del compositor Gerardo Guevara.

- El Albazo: carácter animado de danza con texto, se escribe en compás binario de 6/8 en tonalidad menor. Ejemplo: Albazo del compositor Gerardo Guevara.

- El Aire típico: carácter alegre de danza con texto. Se escribe en compás de $3 / 4,3 / 8$ o $6 / 8$, tempo vivo.

- El Sanjuanito: danza con texto. Se escribe en compás binario de $2 / 4$, tonalidad menor, de mucha aceptación, especialmente en la región andina.

- El Pasillo: canción y baile popular. Se escribe en compás de $3 / 4$, generalmente en tonalidad menor y predomina la pentafonía andina. Su estructura generalmente responde a la forma $\mathrm{A}-\mathrm{B}-\mathrm{B}$; $\mathrm{a}$ veces $A-B-C$; con introducción o estribillo de 4 a 8 compases. El pasillo no sólo se desarrolló en Venezuela, Colombia y Ecuador, sino que por los procesos normales de difusión, también fue aceptado en Costa Rica y Cuba. Un ejemplo de este género musical es el Pasillo El Espantapájaros del compositor Gerardo Guevara.

\section{CONCLUSIONES Y RECOMENDACIONES}

Tal como se ha visto a lo largo del artículo, se puede concluir que el nacionalismo no solo es aplicable a la política o a la religión, sino que también puede encontrarse en las artes, tales como la música, la pintura, la escultura, la literatura, entre otras.

Debido a que la gran parte de la población en el Ecuador es mestiza, y estos ignoran o se aver- güenzan de sus orígenes indígenas, se puede decir que existe una pobre identidad nacional en el Ecuador.

Después de haber identificado y abordado los principales géneros musicales que se utilizan en el Ecuador, se puede observar que el Yaraví, el Danzante, el Yumbo, el Sanjuanito y el Pasillo, son los principales géneros andinos que utiliza el compositor Gerardo Guevara para expresar su carácter nacionalista. Utiliza tonalidades menores y el uso de la pentafonía andina en la mayoría de sus composiciones. Destaca el uso del idioma quichua en la letra de gran parte de sus canciones andinas. También es importante señalar que a pesar de haber recibido enseñanza de maestros europeos, tales como la maestra Nadia Boulanger, el compositor no se dejó influenciar y mantuvo el carácter nacionalista en sus obras.

Se recomienda una mayor difusión de la música nacional a través de los diversos conciertos en vivo y medios de comunicación tales como la radio, la televisión, revistas especializadas e internet. También se recomienda el desarrollo de concursos de composición de música nacional, con el auspicio de empresas estatales y privadas. Asimismo, en los conciertos de música, los intérpretes ecuatorianos deberían incluir al menos una obra de un compositor nacional en sus programas a fin de rescatar nuestra identidad nacional.

\section{REFERENCIAS BIBLIOGRÁFICAS}

Bernal, C. (2010). Metodología de la investigación. Colombia: Pearson Educación.

Godoy, M. (2007). Breve historia de la música del Ecuador. Quito: Corporación Editora Nacional.

Lalama, R. (2011). Ancestros e Identidad. Historia Prehispánica del Ecuador (Tomo I). Guayaquil: Poligráfica.

Lovato, G. (2013). Gerardo Guevara. Músico de cien pueblosy de las prodigiosas capitales. Quito: Excelprint. Morales, F. (1962). Manual de Historia Universal Historia deAmérica (Tomo VI). Madrid: Espasa. Calpe S.A.

Murrieta, K. (1992). Quinientos años. Guayaquil: Fundación Pedro Vicente Maldonado.

Samaniego, F. (2008). Ecuador en la memoria del mundo. Quito: Artes Gráficas Señal Impreseñal Cía. Ltda. 